factors such as hunting, introduced predators, habitat disturbance and destruction, and the illegal bartering of some animals for disreputable zoos. Most of the endangered species are also in their present shaky state through man's unthoughtfulness, and there is now the added weapon of insecticides.

The book's message is not all gloom, however; it reports success stories of animals rescued from the brink and now restored in their native habitats through strict enforcernent of protective measures. Among these animals are the Hawaiian goose, the southern sea otter, and the square lipped rhinoceros.

The Red Book has a message for us all. It is a pleasure to read, and well produced, and the illustrations, some in colour, are of high quality (many were commissioned specially). My only criticism is that there are no photographs of some of the animals in their natural habitats, necessary, I think, if the meaning of nature conservation in its fullest sense is to get anywhere. SARAH Bunney

\section{SCIENTIFIC RUSSIAN}

\section{Practical Scientific Russian}

By S. Kaganoff. Pp. v+342. (Gordon and Breach: New York and London, 1967.) l60s.

THIs is a well printed and well bound textbook of American origin, the aim of which, as stated at the beginning of the introduction, is "to offer detailed guidance . . . for the scientist or engineer who wishes to be able to make his own direct translation of Russian scientific and technical literature".

The major portion of the book is devoted to grammatical chapters, supplemented by a reader, three appendices and a cumulative vocabulary.

Starting with the Russian alphabet, the author does not suggest any transliteration system. This may confuse a beginner while transliterating the Cyrillic alphabet into English. Reference, for instance, to the systom used by the World List of Scientific Periodicals would be appropriate. The following twenty-three grammatical chapters represent in short, word elements, parts of speech, the simple sentence, modifiers, compound and cornplex sentences and punctuation marks.

For its content, this is an expensively priced publication, and the reasons for such a high price are not immediately obvious.

Out of about 4,300 words shown in the cumulative vocabulary, more than 3,500 words are repeated throughout the book in a form of "Vocabulary for Exercise". The information contained in the appendices is offered in a somewhat lavish, overlapping way. At the same time one might feel strongly the absence of a list of abbrevia. tions, which is a necessity in scientific literature. Some abbreviations (for example, $\mathbf{T}-\mathbf{P}$ for temperatures on page 5l) are used but without any explanation to the reader. In opposition to this brevity the reader will find in the "Vocabulary for Exercise" on page 232 the conjunction $И$ which has been used already on more than 50 pages.

While appreciating the standard of reproduction, I cannot congratulate the author and editors on the absence of error's. The work is marred by an inexeusable number of infelicities, such as УЧИТЕЛЬЛ (page 15) and ЧЕТЫРМЬЯ (page 51), persistent mistakes in stress and even inaccuracies in the English text (page 67). The whole work should be submitted for intensive revision. In spite of these reservations, however, this is a useful addition to Russian textbook literature.

The abundance of frequently used idioms and expressions in the examples and exercises will make the book particularly attractive to physicists and also to engineers concerned with the application of electronics.

V. BaLASHOV

\section{Obituaries}

\section{Dr Alastair C. Frazer}

The untimely death of Dr Alastair C. Frazer has robbed British nutritional science of one of its leading and most colourful exponents, for Dr Frazer enjoyed life, good food and wine as much as he enjoyed teaching, research and latterly committeemanship. Born in 1909 and educated at Lancing School and St Mary's Hospital Medical School, he became a lecturer and then acting professor in physiology and pharmacology at the hospital. In 1943 he moved to the University of Birmingham where until 1967 he was professor of medical biochemistry and pharmacology. His research interests ranged from fat absorption and metabolism and the properties of oilwater interfaces to food research and toxicology. With such broad interests, and energy and enthusiasm to mateh thern, Dr Frazer was uniquely able to serve on a host of government and industrial committees. A few weeks ago he accepted the chairmanship of the Dunlop Committee, having previously been chairman of one of its subcommittees (Nature, 222, 1016; 1969). He was also chairman of the Food Research Committee, a member of the Agricultural Research Council, scientific adviser to the Ministry of Agriculture, Fisheries and Food, honorary consultant to the British Army on metabolic diseases, consultant to the UKAEA and a member of the FAO/ WHO Joint Advisory Panel on Food Additives.

Dr Frazer had the great gift of being able to apply levelheadedly the results of academic research to the practical needs of the food and pharmaceutical industries. Unlike some other nutritional biochemists he was unwilling to Iend his name to propaganda campaigns against particular foods or food additives until the scientific evidence was strong enough to be really convineing. Nor did he approve of food companies knocking one another, as, for example, during the most recent cyclamate scare. As a result he won the confidence of the food industry without apparently selling his soul to it, and was president of both the British Food Manufacturing Industries Research Association and the British Industrial Biological Research Association, the two rescarch associations chiefly concerned with the biochemistry of food. He firmly believed that both the food and pharmaceutical industries were best left with the responsibility of ensuring the safety of their products, arguing that they knew only too well that that was where their own interests lay. His regret that the gentlemen's agrecment between the Dunlop Committee and the pharmaceutical industry on the procedures for licensing now drugs and formulations is to bo replaced by more formal procedures under the Medicines Act, and his dislike of the suggestion that Britain needs an organization with the power of the US Food and Drug Administration, are characteristic examples of his philosophy of industrial responsibility.

Since resigning his chair at Birmingham in 1967, Dr Frazer's chief achievement had been the establishment of the British Nutrition Foundation, an independent organization financed by the food industry (Nature, 220,$118 ; 1968$ ) of which he was the first director-general. He intended to mould the foundation into something akin to a CIBA Foundation for nutritional biochemistry; his plans included running international symposia for research scientists at one end of the scale, to creating an informed public opinion by publicizing topical nutritional research through radio, television and the foundation's own Information Bulletin, at the other. 